\title{
Article \\ Impact of Diabetes on Cardiac Function in Patients with High Blood Pressure
}

\author{
Nabila Soufi Taleb Bendiab ${ }^{1}$ (D), Souhila Ouabdesselam ${ }^{2,3}$, Latefa Henaoui ${ }^{4}$, Marilucy Lopez-Sublet ${ }^{5,6}$, \\ Jean-Jacques Monsuez ${ }^{5, *(D)}$ and Salim Benkhedda ${ }^{2,3}$ (D)
}

Citation: Soufi Taleb Bendiab, N.; Ouabdesselam, S.; Henaoui, L.; Lopez-Sublet, M.; Monsuez, J.-J.; Benkhedda, S. Impact of Diabetes on Cardiac Function in Patients with High Blood Pressure. Int. J. Environ. Res. Public Health 2021, 18, 6553. https://doi.org/10.3390/ ijerph18126553

Academic Editors: Antonio Scarano, Biagio Rapone and

Maurizio Delvecchio

Received: 13 May 2021

Accepted: 14 June 2021

Published: 18 June 2021

Publisher's Note: MDPI stays neutral with regard to jurisdictional claims in published maps and institutional affiliations.

Copyright: (c) 2021 by the authors. Licensee MDPI, Basel, Switzerland. This article is an open access article distributed under the terms and conditions of the Creative Commons Attribution (CC BY) license (https:/ / creativecommons.org/licenses/by/ $4.0 /)$.
1 Department of Cardiology, Faculty of Medicine Aboubekr Belkaid, University Hospital Tlemcen, Tlemcen 13000, Algeria; sarra13dz@yahoo.fr

2 Department of Cardiology, Mustapha University Hospital Center Algiers, Algiers 16000, Algeria; souhila85@hotmail.com (S.O.); sbenkhedda@gmail.com (S.B.)

3 Cardiology Oncology Research Collaborative Group (CORCG), Faculty of Medicine BENYOUCEF BENKHEDDA University, Algiers 16000, Algeria

4 Department of Epidemiology, Faculty of Medicine Aboubekr Belkaid, University Hospital Tlemcen, Tlemcen 13000, Algeria; henaouilatifa@yahoo.fr

5 APHP Hôpital R Muret, Hôpitaux Universitaires de Paris Seine Saint Denis, 93270 Sevran, France; marilucy.lopez-sublet@aphp.fr

6 Centre d'HTA, Hôpital Avicenne,93000 Bobigny, France

* Correspondence: jean-jacques.monsuez@aphp.fr; Tel.: +33-1-41525832; Fax: +33-1-141525816

Abstract: Background: Although the combination of high blood pressure (HBP) and type 2 diabetes (T2DM) increases the risk of left ventricular (LV) dysfunction, the impact of T2DM on LV geometry and subclinical dysfunction in hypertensive patients and normal ejection fraction (EF) has been infrequently evaluated. Methods: Hypertensive patients with or without T2DM underwent cardiac echocardiography coupled with LV global longitudinal strain (GLS) assessment. Results: Among 200 patients with HBP (mean age $61.7 \pm 9.7$ years) and EF > 55\%, 93 had associated T2DM. Patients with T2DM had a higher body mass index $\left(29.9 \pm 5.1 \mathrm{~kg} / \mathrm{m}^{2}\right.$ vs. $\left.29.3 \pm 4.7 \mathrm{~kg} / \mathrm{m}^{2}, p=0.025\right)$, higher BP levels (158 $\pm 23 / 95 \pm 13$ vs. $142 \pm 33 / 87 \pm 12 \mathrm{mmHg}, p=0.003)$, a higher LV mass index $\left(115.8 \pm 32.4\right.$ vs. $\left.112.0 \pm 24.7 \mathrm{~g} / \mathrm{m}^{2}, p=0.004\right)$, and higher relative wall thickness $(0.51 \pm 0.16$ vs. $0.46 \pm 0.12, p=0.0001)$. They had more frequently concentric remodeling $(20.4 \% \mathrm{vs} .16 .8 \%$, $p<0.001)$, concentric hypertrophy $(53.7 \%$ vs. $48.6 \%, p<0.001)$, elevated filling pressures (25.8 vs. $12.1 \%, p=0.0001)$, indexed left atrial volumes greater than $28 \mathrm{~mL} / \mathrm{m}^{2}(17.2 \mathrm{vs} .11 .2 \%, p=0.001)$, and a reduced GLS less than $-18 \%(74.2$ vs. $47.7 \%, p<0.0001)$. After adjustment for BP and BMI, T2DM remains an independent determinant factor for GLS decline (OR $=2.26,95 \%$ CI 1.11-4.61, $p=0.023)$. Conclusions: Left ventricular geometry and subclinical LV function as assessed with GLS are more impaired in hypertensive patients with than without T2DM. Preventive approaches to control BMI and risk of T2DM in hypertensive patients should be emphasized.

Keywords: diabetes; hypertension; left ventricular function; global longitudinal strain

\section{Introduction}

The colluding effects of the two most common noncommunicable diseases, hypertension and type 2 diabetes mellitus (T2DM), result in a severalfold elevation in risk for cardiovascular morbidity and mortality [1]. Hypertension is associated with left ventricular (LV) remodeling [2]. Pressure overload results in increased wall thickness and LV mass, and, in turn, in diastolic dysfunction resulting from collagen deposition [1,2]. Although effective control of HBP allows most patients to remain asymptomatic for many years, LV hypertrophy, diastolic dysfunction, and heart failure may develop overtime, suggesting that early recognition of subclinical cardiac damage may be useful [2,3].

The prevalence of hypertension is significantly higher in diabetic patients, as high as $50-70 \%$ in some studies, and, reciprocally, T2DM is commonly associated in hypertensive 
patients [4]. In addition, diabetes also impairs LV structure and function, leading to diastolic dysfunction and decreased LV function [5].

The association of HBP and T2DM further increases the risk of progressive LV dysfunction and heart failure [6]. Although previous studies have observed more severe subclinical systolic dysfunction in patients with coexisting T2DM and hypertension than in patients with T2DM only [7,8], none have evaluated the impact of T2DM on LV geometry and LV subclinical dysfunction in patients with hypertension.

Although two-dimensional echocardiography (2-DE) may track changes in LV diastolic and systolic function, assessment of LV global longitudinal strain (GLS) by speckletracking provides recognition of LV impairment and its associated factors at an earlier stage [9].

This study investigates the impact on subclinical cardiac function of concomitant diabetes in a cohort of patients with HBP.

\section{Methods}

\subsection{Patients}

This cross-sectional study was conducted in 200 hypertensive patients aged $\geq 30$ years and followed up in an outpatient clinic between January 2018 and January 2019. There were 93 patients with and 107 without concomitant T2DM. All had normal LV ejection fraction (EF) defined as $\mathrm{EF}>55 \%$. Hypertension was defined by a systolic blood pressure (BP) $\geq 140 \mathrm{mmHg}$, a diastolic BP $\geq 90 \mathrm{mmHg}$, or both, or current treatment for HBP. Patients with secondary hypertension, concomitant cardiomyopathy, heart failure, moderate to severe valve heart disease, coronary artery disease, atrial fibrillation, or paced cardiac rhythm were not included.

The study was approved by the committee for ethics of the Mustapha hospital. All patients gave formal informed consent.

\subsection{Clinical Assessment}

Patients' past medical history, including cardiovascular risk factors, duration, treatment and control of HBP, as well as baseline clinical characteristics, including age, gender, weight, height, and body mass index (BMI) were recorded. HBP was classified using the European Society of Hypertension and the European Society of Cardiology guidelines [10,11] Brachial BP was measured using a sphygmomanometer cuff after a 5 min rest period in a seated position before echocardiographic examination. The mean of two consecutive readings was calculated and retained for analysis.

Blood sampling included glucose and creatinine level determinations. Creatinine clearance was calculated using the MDRD formula. Lipid profile determination included total cholesterol, LDL-cholesterol, HDL-cholesterol, and triglyceride levels.

$\mathrm{LVH}$ was defined using the Sokolow-Lyon index obtained from a resting 12-lead electrocardiogram examination.

\subsection{Echocardiographic Assessment}

Ultrasound examination included 2DE imaging, M-mode evaluation, a Dopplercoupled analysis using pulsed, continuous, and color methods, and a 2-dimensional strain measurement (2D strain) using a harmonic $4.0 \mathrm{MHz}$ variable-frequency phased-array transducer VIVID S6 ultrasound system (General Electric Healthcare, Milwaukee, WI, USA). The same experienced physician performed all examinations with the patient in the left lateral position along the parasternal long-axis view, short axis, and apical 2, 3, and 4 cavities. Records connected to an ECG were obtained from 3 consecutive cardiac cycles at each plane at end-expiration breath, as recommended by the American Society of Echocardiography [12]. 


\subsubsection{Cardiac Geometry}

M-mode derived measurements of end-diastolic LV diameter (Dd), end-systolic LV diameter (Ds), end-diastolic thickness of the ventricular septum (VST), and end-diastolic thickness of the LV posterior wall (PWT) allowed calculation of LV mass and relative LV wall thickness (RWT) as follows:

- $\quad$ LV mass $(\mathrm{g})=0.8 \times 1.04 \times\left[(\mathrm{Dd}+\mathrm{PWT}+\mathrm{VST})^{3}-\mathrm{Dd}^{3}\right]+0.6$

- $\quad$ RWT $=2 \times \mathrm{PWT} / \mathrm{Dd}$

LV mass was indexed to body surface area (LVMI). Left ventricular hypertrophy was defined by an LVMI $>115 \mathrm{~g} / \mathrm{m}^{2}$ in men and $>95 \mathrm{~g} / \mathrm{m}^{2}$ in women, except for obese patients in whom $\mathrm{LVH}$ was defined as $>49 \mathrm{~g} / \mathrm{m}^{2.7}$ in men and $>45 \mathrm{~g} / \mathrm{m}^{2.7}$ in women [8-11].

According to the ASE guidelines, cardiac geometry of patients was classified using RWT and LVMI as follows: (1) normal geometry (normal RWT and LVMI); (2) concentric remodeling (normal LVMI, increased RWT); (3) concentric hypertrophy (RWT and LVMI both increased); or (4) eccentric hypertrophy (normal RWT, increased LVMI) [7]. Left atrial (LA) end-systolic volume was also measured.

\subsubsection{Cardiac Function}

The Simpson's 2-chambers and 4-chambers biplane method was applied to measure LV ejection fraction (EF). Transmitral flow velocities measured by pulsed Doppler were used to assess LV diastolic function, including peak early diastolic velocity (E), deceleration time from the peak of the early diastolic wave to baseline, peak atrial systolic velocity (A), and the E/A ratio. Velocities of mitral annular motion were measured at the LV septal and lateral annulus by pulsed tissue Doppler assessment, allowing calculation of peak early diastolic motion velocity $\left(E^{\prime}\right)$, mean $E^{\prime}\left(E^{\prime}\right.$ septal + E'lateral/2), and the ratio $E / E^{\prime}$.

The maximum velocity of the tricuspid regurgitation jet allowed calculation of pulmonary artery systolic pressure.

\subsection{Two-Dimensional Strain Imaging}

Using the speckle tracking technique, velocities, strain curves, and systolic longitudinal strain were measured from apical long-axis views at end-expiration breath of 3 consecutive cardiac cycles, allowing determination of the global longitudinal peak systolic strain (GLS) to assess LV ventricular function [9].

\section{Statistical Analysis}

Comparisons of continuous variables expressed as mean values \pm standard deviation (SD) were performed using ANOVA. Comparisons of categorical variables were performed using the chi-square test or the Fisher exact test when appropriate. Data analysis was performed using SSPS software (Graduate Pack for Windows, version 20) (IBM, Armonk, NY, USA). A $p$-value $<0.05$ was considered significant.

\section{Results}

\subsection{Baseline Characteristics}

Mean age of the 200 hypertensive patients (39\% men, 61\% women) included was $61.7 \pm 9.7$ years. In most (71\%), HBP lasted for at least 5 years. All patients were of the same Northern African ethnicity, born and living in Algeria. BMI was $29.9 \pm 5.1 \mathrm{~kg} / \mathrm{m}^{2}$ in diabetics versus $29.3 \pm 4.7 \mathrm{~kg} / \mathrm{m}^{2}$ in patients without T2DM $(p=0.025)$. Systolic blood pressure was slightly higher in diabetics versus nondiabetic patients. Baseline clinical characteristics of the study population are listed in Table 1. 
Table 1. General characteristics of the study population.

\begin{tabular}{cccc}
\hline & Hypertension and T2DM, & Hypertension without T2DM, & $\boldsymbol{n}$-Value \\
& $\boldsymbol{n}=\mathbf{9 3}$ & $62 \pm 6.4$ & 0.64 \\
\hline Age, years & $61 \pm 9.7$ & 0.87 & 0.88 \\
\hline M/F & 0.57 & $29.3 \pm 4.7$ & 0.025 \\
\hline Body mass index, $\mathrm{kg} / \mathrm{m}^{2}$ & $29.9 \pm 5.1$ & $142 \pm 33$ & 0.002 \\
\hline Systolic BP, $\mathrm{mmHg}$ & $158 \pm 23$ & $87 \pm 12$ & 0.003 \\
\hline Diastolic BP, $\mathrm{mmHg}$ & $95 \pm 13$ & $9(8.4 \%)$ & 0.003 \\
\hline Chronic kidney disease, $n$ & $13(13.9 \%)$ & $28(26.1 \%)$ & 0.46 \\
\hline Dyslipidemia, $n$ & $27(29 \%)$ & & \\
\hline
\end{tabular}

BP: blood pressure; M/F: men/women; T2DM: type 2 diabetes.

\subsection{Cardiac Geometry and Function}

Echocardiographic findings of the patients are listed in Table 2. LVH was observed in $65 \%$ of patients with and $61 \%$ of those without T2DM, with a mean LVMI of $115.8 \pm 32.4$ versus $112.0 \pm 24.7 \mathrm{~g} / \mathrm{m}^{2}$, respectively $(p=0.004)$. Concentric remodeling was found in $20.4 \%$ versus $16.8 \%$ of patients with and without $\mathrm{T} 2 \mathrm{DM}$, and concentric hypertrophy in $53.7 \%$ versus $48.6 \%$, respectively ( $p<0.001$ for both).

Table 2. Echocardiographic characteristics of the study population.

\begin{tabular}{|c|c|c|c|}
\hline & $\begin{array}{l}\text { Hypertension with T2DM, } \\
\qquad n=93\end{array}$ & $\begin{array}{l}\text { Hypertension without TDM, } \\
\qquad n=107\end{array}$ & $p$-Value \\
\hline $\mathrm{LA}, \mathrm{cm}$ & $39.4 \pm 5.6$ & $38.6 \pm 5.8$ & 0.25 \\
\hline LA volume index $\mathrm{mL} / \mathrm{m}^{2}$ & $17.4 \pm 7.4$ & $6.5 \pm 7.0$ & 0.004 \\
\hline Relative wall thickness & $0.51 \pm 0.16$ & $0.46 \pm 0.12$ & 0.0001 \\
\hline LV mass index, $\mathrm{g} / \mathrm{m}^{2}$ & $115.8 \pm 32.4$ & $112.0 \pm 24.7$ & 0.007 \\
\hline LV ejection fraction, $\%$ & $61.4 \pm 6.0$ & $61.6 \pm 6.3$ & 0.63 \\
\hline Midwall fractional shortening, $\%$ & $35.1 \pm 7.1$ & $35.0 \pm 6.6$ & 0.45 \\
\hline Normal LV geometry, $n$ & $9(9.7 \%)$ & $25(23.3 \%)$ & 0.0003 \\
\hline Concentric remodeling, $n$ & $19(20.4 \%)$ & $18(16.9 \%)$ & $<0.0001$ \\
\hline Concentric hypertrophy, $n$ & $50(53.7 \%)$ & $52(48.6)$ & $<0.0001$ \\
\hline Eccentric hypertrophy, $n$ & $15(16.1 \%)$ & $12(11.2 \%)$ & 0.002 \\
\hline $\mathrm{E} / \mathrm{A}$ ratio & $0.8 \pm 0.5$ & $0.7 \pm 0.3$ & 0.25 \\
\hline $\mathrm{E} / \mathrm{E}^{\prime}$ ratio & $6.8 \pm 2.7$ & $6.4 \pm 2.4$ & $<0.0001$ \\
\hline GLS, \% & $-16.4 \pm 3.0$ & $-17.8 \pm 3.2$ & $<0.0001$ \\
\hline
\end{tabular}

E/A: early to late mitral filling velocity ratio; E/E': average mitral-to-peal early diastolic annular ratio; GLS: global longitudinal strain; LA: left atrial; LV: left ventricular; T2DM: type 2 diabetes.

RWT was $>0.42$ in 144 patients $(72 \%)$. Mean RWT was higher in patients with than without T2DM ( $0.51 \pm 0.16$ vs. $0.46 \pm 0.12, p=0.0001)$.

An impaired diastolic function was seen in $178(89 \%)$ patients. Elevated filling pressures were observed in 24 patients with and 13 patients without T2DM (25.8 vs. $12.1 \%$, $p=0.0001)$.

Indexed left atrial volumes $>28 \mathrm{~mL} / \mathrm{m}^{2}$ were observed in 16 patients with and 12 patients without T2DM (17.2 vs. $11.2 \%, p=0.001)$. 


\subsection{Global Myocardial Strain}

Mean GLS values obtained from apical 3- and 4-chamber views were lower in hypertensive patients with than in those without T2DM (Table 3). A reduced GLS less than $-18 \%$ was observed in 69 patients with and 51 patients without T2DM (74.2 vs. $47.7 \%, p<0.0001)$.

Table 3. Two-way analysis of variance of effects of diabetes, systolic blood pressure, and their interaction.

\begin{tabular}{ccccc}
\hline & df & MS & F-Statistic & $p$-Value \\
\hline T2DM & 1 & 64.86 & 6.5 & 0.01 \\
\hline SBP & 1 & 92.27 & 9.25 & 0.003 \\
\hline T2DM * SBP & 1 & 8.12 & 0.89 & 0.368 \\
\hline Standard error & 42 & 9.96 & &
\end{tabular}

* On global longitudinal strain. df: degree of freedom; MS: mean square; SBP: systolic blood pressure; T2DM: type 2 diabetes.

\subsection{Multivariate Analysis}

Although hypertensive patients with T2DM have higher blood pressure levels and higher BMI than those without T2DM, after adjustment for blood pressure and BMI using ANOVA, T2DM remains an independent determinant factor for GLS decline (Tables 3 and 4). Independent factors of lower GLS risk resulting from logistic regression in hypertensive patients are listed in Table 5. They include non-control of blood pressure, BMI, diabetes, and RWT.

Table 4. Two-way analysis of variance of effects of diabetes, overweight, and their interaction * on global longitudinal strain.

\begin{tabular}{ccccc}
\hline & df & MS & F-Statistic & $p$-Value \\
\hline T2DM & 1 & 67.04 & 6.50 & 0.01 \\
\hline Overweight & 1 & 39.90 & 3.77 & 0.05 \\
\hline T2DM * Overweight & 1 & 5.77 & 0.56 & 0.45 \\
\hline Standard error & 196 & 10.30 & & \\
\hline df: degree of freedom; MS: mean square; T2DM: type 2 diabetes. & & &
\end{tabular}

Table 5. Independent factors of lower GLS risk resulting from logistic regression in hypertensive patients. Adjusted odds ratio (OR) and associated $95 \%$ confidence interval (CI).

\begin{tabular}{cccc}
\hline Risk Factor & OR & $\mathbf{9 5 \% ~ C I}$ & $\mathbf{p}^{\mathbf{b}}$ \\
\hline Non control of BP & 8.8 & $2.3-34.2$ & 0.001 \\
\hline BMI & 0.2 & $0.04-1.04$ & 0.005 \\
\hline T2DM & 2.26 & $1.11-4.61$ & 0.023 \\
\hline RWT & 5.18 & $1.84-6.02$ & 0.001 \\
\hline
\end{tabular}

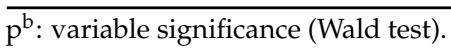

\subsection{Impact of HBP Treatment}

Among the four classes of hypertensive drugs administered to patients (angiotensinconverting enzyme inhibitors, diuretics, beta-blocking agents, calcium channel inhibitors), the angiotensin-converting enzyme inhibitors provided a protective effect in patients with HBP and T2DM (Table 6). 
Table 6. Impact of treatment of HBP on GLS outcome.

\begin{tabular}{|c|c|c|c|c|c|c|}
\hline \multirow[b]{2}{*}{ GLS } & \multicolumn{3}{|c|}{ Non Diabetics } & \multicolumn{3}{|c|}{ Diabetics } \\
\hline & Patients, $n$ & Normal, \% & Reduced, \% & Patients, $n$ & Normal, \% & Reduced, $\%$ \\
\hline \multirow[t]{2}{*}{ ACEI } & Without, 72 & 43 & 56 & Without, 78 & 20.5 & 79.5 \\
\hline & With, 35 & 71 & 28.5 & With, 15 & 53.3 & 46.3 \\
\hline \multirow[t]{2}{*}{$\mathrm{D}$} & Without, 60 & 61 & 38.3 & Without, 39 & 30.7 & 46.7 \\
\hline & With, 47 & 40.4 & 59.6 & With, 54 & 22.2 & 72.7 \\
\hline \multirow[t]{2}{*}{$\mathrm{BB}$} & Without, 84 & 55.9 & 44 & Without, 77 & 28.5 & 71.4 \\
\hline & With, 23 & 39.1 & 61.8 & With, 16 & 12.5 & 87.5 \\
\hline \multirow[t]{2}{*}{ CCA } & Without, 79 & 55.6 & 44.3 & Without, 59 & 28.8 & 71.1 \\
\hline & With, 28 & 42.8 & 57.1 & With, 34 & 20.5 & 79.4 \\
\hline
\end{tabular}

ACEI: angiotensin-converting enzyme inhibitors; BB: beta-blocking agents; CCA: calcium channel antagonists; D: diuretics; GLS: global longitudinal strain.

\section{Discussion}

A decreased GLS has been reported previously in $15 \%$ to $42 \%$ of patients with HBP, depending on both severity and control of HBP [13-16]. In addition, GLS is more reduced in patients with long-lasting HBP, overweight, metabolic changes, and diabetes [16]. On the other hand, early impairment of GLS is observed in patients with T2DM [5,17], which is worsened by coexistent hypertension [18-20].

The present study shows two main results: despite a conserved LV ejection fraction, (1) LV geometry is more impaired in hypertensive patients with than in those without T2DM. The former are more prone to concentric remodeling and concentric hypertrophy than the latter; (2) coexisting T2DM further deteriorates LV subclinical function as assessed with GLS in patients with HBP.

These findings are consistent with those reported by Li et al., using cardiac magnetic resonance to assess GLS in hypertensive patients with or without T2DM [21]. Both indicate the deleterious effect of T2DM on myocardial function in patients with hypertension. Such a subclinical impairment should be detected as early as possible to optimize treatment and blood pressure control in these high-risk patients.

The mechanisms by which T2DM further impairs subclinical LV function in hypertensive patients remain unclear. Factors associated with impaired geometry and decreased GLS in patients with hypertension include duration of hypertension, uncontrolled hypertension, LV hypertrophy, overweight, and related metabolic changes [16]. More specific effects of diabetes have also been reported to contribute to LV dysfunction. Direct effects of insulin resistance/hyperglycemia on the myocardium may contribute to a condition generally referred to as diabetic cardiomyopathy, including mitochondrial dysfunction, endoplasmic reticulum stress, oxidative stress, production of advanced glycosylation end products, impaired calcium homeostasis, renin-angiotensin-aldosterone system activation, and microvascular dysfunction [5]. A recent MRI study showed a significant correlation between subclinical LV dysfunction and impaired myocardial perfusion in hypertensive patients with diabetes. Abnormalities of the microvascular perfusion may compromise nutrients and oxygen delivery, energy production, and, in turn, myocardial contractility [21].

\subsection{Preventive Implications}

Since simultaneous occurrence of T2DM further impacts myocardial function of hypertensive patients, overweight and subsequent metabolic changes should be avoided among them. Optimal control of glycemia and control of cardiovascular risk factors, especially HBP, are associated with a decrease in all-cause mortality and cardiovascular mortality [22]. Indeed, weight loss has been reported to improve cardiac structure and function of patients with overweight [23]. Accordingly, effective and optimal treatment of HBP should be obtained in very high risk hypertensive patients such as those with T2DM [24]. In addition, 
antihypertensive drugs such as angiotensin-converting enzyme inhibitors, as observed in the present study, may have direct protective effects, and their use may contribute to reduced vascular complications in patients with HBP and concomitant T2DM [25].

\subsection{Limitations of the Study}

A first limitation pertains to the evaluation of subclinical LV function using GLS only. This was done according to the fact that patients included were free of any cardiac disease other than HBP, including coronary artery disease and regional wall motion abnormality. A second limitation results from the fact that wall stress impacts GLS. However, in the multivariable analysis of our study, T2DM and RWT remained independent risk factors for GLS decline.

\section{Conclusions}

Left ventricular geometry and subclinical LV function measured with GLS are more impaired in hypertensive patients with than in those without T2DM. Preventive approaches to control BMI and risk of T2DM in hypertensive patients should be emphasized.

Author Contributions: N.S.T.B., S.O., L.H., M.L.-S., J.-J.M. and S.B. contributed to the conception and design of the work. N.S.T.B., S.O., L.H., M.L.-S., J.-J.M. and S.B. contributed to the acquisition, analysis and interpretation of data of the work. J.-J.M. drafted the manuscript. M.L.-S., J.-J.M. and S.B. critically revised the manuscript. All gave final approval and agreed to be accountable for all aspects of work ensuring integrity and accuracy. All authors have read and agreed to the published version of the manuscript.

Funding: This research received no external funding and was performed by the COCRG: Cardiology Oncology Research Collaborative Group (CORCG), Department of Cardiology, CHU Mustapha, Faculty of Medicine BENYOUCEF BENKHEDDA University, Algiers, Algiers.

Institutional Review Board Statement: The study was conducted according to the guidelines of the Declaration of Helsinki, and approved by the Ethics Committee of Centre hospitalier Mustapha on 12 December 2018.

Informed Consent Statement: Informed consent was obtained from all subjects involved in the study.

Data Availability Statement: Data are available on the dept of cardiology ( $\operatorname{Pr} S$ Benkhedda), Hospital Mustapha; Algiers.

Conflicts of Interest: The authors declare no conflict of interest.

\section{References}

1. Ferrannini, E.; Cushman, W.C. Diabetes and hypertension: The bad companions. Lancet 2012, 380, 601-610. [CrossRef]

2. Kannan, A.; Janardhanan, R. Hypertension as a Risk Factor for Heart Failure. Curr. Hypertens. Rep. 2014, 16, 1-8. [CrossRef]

3. Wagner, M.; Tiffe, T.; Morbach, C.; Gelbrich, G.; Stoerk, S.; Heuschmann, P.U. Characteristics and course of heart failure stages A-B and determinants of progression. Eur. J. Prev. Cardiol. 2017, 24, 468-479. [CrossRef]

4. Rapsomaniki, E.; Timmis, A.; George, J.; Rodriguez, M.P.; Shah, A.D.; Denaxas, S.; White, I.R.; Caulfield, M.J.; Deanfield, J.; Smeeth, L.; et al. Blood pressure and incidence of twelve cardiovascular diseases: Lifetime risks, healthy life-years lost, and age-specific associations in 1.25 million people. Lancet 2014, 383, 1899-1911. [CrossRef]

5. Ferrini, M.; Johansson, I.; Aboyans, V. Heart failure and its complications in patients with diabetes: Mounting evidence for a growing burden. Eur. J. Prev. Cardiol. 2019, 26, 106-113. [CrossRef]

6. Tocci, G.; Sciarretta, S.; Volpe, M. Development of heart failure in recent hypertension trials. J. Hypertens. 2008, 26, 1477-1486. [CrossRef]

7. Tadic, M.; Cuspidi, C.; Vukomanovic, V.; Ilic, S.; Obert, P.; Kocijancic, V.; Celic, V. Layer-specific deformation of the left ventricle in uncomplicated patients with type 2 diabetes and arterial hypertension. Arch. Cardiovasc. Dis. 2018, 111, 17-24. [CrossRef]

8. Mannina, C.; Jin, Z.; Russo, C.; Homma, S.; Elkind, M.S.; Rundek, T.; Lee, T.C.; Matsumoto, K.; Shames, S.; Sacco, R.L.; et al. Effect of hypertension and diabetes on subclinical left ventricular systolic dysfunction in a predominantly elderly population-based cohort. Eur. J. Prev. Cardiol. 2020, 27, 2173-2175. [CrossRef]

9. Leitman, M.; Lysyansky, P.; Sidenko, S.; Shir, V.; Peleg, E.; Binenbaum, M.; Kaluski, E.; Krakover, R.; Vered, Z. Two-dimensional strain-a novel software for real-time quantitative echocardiographic assessment of myocardial function. J. Am. Soc. Echocardiogr. 2004, 17, 1021-1029. [CrossRef] [PubMed] 
10. European Society of Hypertension and European Society of Cardiology. Guidelines for the management of arterial hypertension. European Society of Hypertension and European Society of Cardiology. J. Hypertens. 2007, 25, 1105-1187.

11. National Committee on Prevention, Detection, Evaluation, and Treatment of High Blood Pressure. The Seventh Report of the Joint National Committee on Prevention, Detection, Evaluation, and Treatment of High Blood Pressure: The JNC 7 Report. JAMA 2003, 289, 2560-2572. [CrossRef]

12. Lang, R.M.; Bierig, M.; Devereux, R.B.; Flachskampf, F.A.; Foster, E.; Pellikka, P.A.; Picard, M.; Roman, M.J.; Seward, J.; Shanewise, J.S.; et al. Recommendations for Chamber Quantification: A Report from the American Society of Echocardiography's Guidelines and Standards Committee and the Chamber Quantification Writing Group, Developed in Conjunction with the European Association of Echocardiography, a Branch of the European Society of Cardiology. J. Am. Soc. Echocardiogr. 2005, 18, 1440-1463. [CrossRef] [PubMed]

13. Kosmala, W.; Plaksej, R.; Strotmann, J.M.; Weigel, C.; Herrmann, S.; Niemann, M.; Mende, H.; Störk, S.; Angermann, C.E.; Wagner, J.A.; et al. Progression of Left Ventricular Functional Abnormalities in Hypertensive Patients with Heart Failure: An Ultrasonic Two-Dimensional Speckle Tracking Study. J. Am. Soc. Echocardiogr. 2008, 21, 1309-1317. [CrossRef]

14. Imbalzano, E.; Zito, C.; Carerj, S.; Oreto, G.; Mandraffino, G.; Di Bella, G.; Saitta, C.; Saitta, A.; Cusmà-Piccione, M. Left Ventricular Function in Hypertension: New Insight by Speckle Tracking Echocardiography. Echocardiography 2011, 28, 649-657. [CrossRef]

15. Ayoub, A.M.; Keddeas, V.W.; Ali, Y.A.; El Oki, R.A. Subclinical LV dysfunction detection using specle tracking echocardiography in hypertensive patients with preserved LV ejection fraction. Clin. Med. Insights Cardiol. 2016, 10, 85-90. [CrossRef]

16. Soufi Taleb Bendiab, N.; Meziane-Tani, A.; Ouabdesselam, S.; Methia, N.; Latreche, S.; Henaoui, L.; Benkhedda, S. Factors associated with global longitudinal strain decline in hypertensive patients with normal left ventricular ejection fraction. Eur. J. Prev. Cardiol. 2017, 14, 1133-1135. [CrossRef]

17. Wang, Q.; Gao, Y.; Tan, K.; Xia, H.; Li, P. Assessment of left ventricular function by three-dimensional speckle-tracking echocardiography in well-treated type 2 diabetes patients with or without hypertension. J. Clin. Ultrasound 2015, 43, 502-511. [CrossRef] [PubMed]

18. Muranaka, A.; Yuda, S.; Tsuchihashi, K.; Hashimoto, A.; Nakata, T.; Miura, T.; Tsuzuki, M.; Wakabayashi, C.; Watanabe, N.; Shimamoto, K. Quantitative Assessment of Left Ventricular and Left Atrial Functions by Strain Rate Imaging in Diabetic Patients with and without Hypertension. Echocardiography 2009, 26, 262-271. [CrossRef] [PubMed]

19. Enomoto, M.; Ishizu, T.; Seo, Y.; Yamamoto, M.; Suzuki, H.; Shimano, H.; Kawakami, Y.; Aonuma, K. Subendocardial Systolic Dysfunction in Asymptomatic Normotensive Diabetic Patients. Circ. J. 2015, 79, 1749-1755. [CrossRef] [PubMed]

20. Stevanovic, A.; Dekleva, M. The importance of subclinical left ventricular dysfunction and blood pressure pattern in asymptomatic type-2 diabetic patients: The diagnostic and prognostic significance of Tissue Doppler parameters, left ventricular global longitudinal strain, and nighttime blood pressure during sleep. J. Diabetes Complicat. 2018, 32, 41-47. [CrossRef]

21. Li, X.-M.; Jiang, L.; Guo, Y.-K.; Ren, Y.; Han, P.-L.; Peng, L.-Q.; Shi, R.; Yan, W.-F.; Yang, Z.-G. The additive effects of type 2 diabetes mellitus on left ventricular deformation and myocardial perfusion in essential hypertension: A 3.0 T cardiac magnetic resonance study. Cardiovasc. Diabetol. 2020, 19, 1-10. [CrossRef]

22. Rajbhandari, J.; Fernandez, C.J.; Agarwal, M.; Yeap, B.X.Y.; Pappachan, J.M. Diabetic heart disease: A clinical update. World J. Diabetes 2021, 12, 383-406. [CrossRef] [PubMed]

23. Shah, R.V.; Murthy, V.; Abbasi, S.A.; Eng, J.; Wu, C.; Ouyang, P.; Kwong, R.Y.; Goldfine, A.; Bluemke, D.; Lima, J.; et al. Weight loss and progressive left ventricular remodelling: The Multi-Ethnic Study of Atherosclerosis (MESA). Eur. J. Prev. Cardiol. 2015, 22, 1408-1418. [CrossRef] [PubMed]

24. Bendiab, N.S.T.; Benkhedda, S.; Henaoui, L.; Tani, A.M. The Impact of Uncontrolled Hypertension on the Longitudinal Systolic Function of the Left Ventricle. Curr. Hypertens. Rev. 2021, 17. [CrossRef] [PubMed]

25. Petrie, J.R.; Guzik, T.J.; Touyz, R.M. Diabetes, hypertension, and cardiovascular disease: Clinical insights and vascular mechanisms. Can. J. Cardiol. 2018, 34, 575-584. [CrossRef] 